\section{RESEARCH ARTICLE 10.1029/2019JC015637 \\ Modeling the Dispersion of Dissolved Natural Gas Condensates From the Sanchi Incident}

Key Points:

- Dissolved hydrocarbons are the main environmental risk for maritime spills of natural gas condensates

- Natural gas condensates are much more soluble than crude oil, and the dissolved condensates are spread afar by ocean currents

- The scope and magnitude of the dispersion are most sensitive to the biodegradation time scales

Correspondence to:

L. Chen, and J. Yang,

chenlei@stu.ouc.edu.cn

jyang@whoi.edu

Citation:

Chen, L., Yang, J., \& Wu, L. (2019).

Modeling the Dispersion of Dissolved

Natural Gas Condensates From the

Sanchi Incident. Journal of Geophysical

Research: Oceans, 124, 8439-8454.

https://doi.org/10.1029/2019JC015637

Received 11 SEP 2019

Accepted 6 NOV 2019

Accepted article online 11 NOV 2019

Published online 30 NOV 2019

(C)2019. American Geophysical Union. All Rights Reserved.

\author{
Lei Chen ${ }^{1,2,3}$ (D) Jiayan Yang ${ }^{3}$, and Lixin $\mathrm{Wu}^{1,2}$ \\ ${ }^{1}$ Key Laboratory of Physical Oceanography/Institute for Advanced Ocean Studies, Ocean University of China, Qingdao, \\ China, ${ }^{2}$ Qingdao National Laboratory for Marine Science and Technology, Qingdao, China, ${ }^{3}$ Department of Physical \\ Oceanography, Woods Hole Oceanographic Institution, Woods Hole, MA, USA
}

\begin{abstract}
An Iranian tanker with 136,000 tons of natural gas condensates collided with a freighter in the East China Sea in January 2018 and, after drifting ablaze for 8 days and over $200 \mathrm{~km}$, capsized on the edge of the shelf near the Kuroshio Current. Different from the crude oil, the condensates consist of hydrocarbons that have relatively high solubility in seawater. We postulate that the leakage from the remaining condensate cargo at $110 \mathrm{~m}$ depth may result in a bottom layer of condensate-enriched water in the vicinity of the resting tanker. A model is constructed in this study to simulate the dispersion of contaminated water through the processes of oceanic advection, diffusion, biodegradation, and volatilization. It is found that the scope and magnitude of the dispersion are most sensitive to the biodegradation. Even though the biodegradation time scale depends on several factors that are not well quantified in this region, using any value within the estimated range from a previous study results in significant contamination in the broad area. The dispersion is particularly effective in this incident because the tanker capsized near the Kuroshio Current-a fast-moving western boundary current. The Kuroshio acts as a fast conduit to spread the contaminant to the east coast of Japan and the interior Pacific Ocean. In addition, we identify that the Tsushima Warm Current, a perennial flow into the Japan Sea, is the second major conduit for spreading the polluted water. This study indicates that dissolved hydrocarbons are the main environmental risk for maritime spills of natural gas condensates.
\end{abstract}

Plain Language Summary The spill of the natural gas condensates in the East China Sea was unprecedented and the first major maritime spill of this kind in history. Unlike the more commonly spilled crude oil, the condensates are highly volatile and become invisible within days. However, the condensates mainly consist of low molecular weight hydrocarbons that have high solubility in seawater. Once dissolved in seawater, it is removed mainly by microbiologic processes that may take months to years. It is postulated in this study that the underwater leakage from the sunken tanker may result in a bottom layer of condensate-enriched water. In this study we formulate a model to examine how the contaminant water spread by oceanic processes. It is found that the scope and magnitude of the dispersion are most sensitive to how long the marine microorganism can consume the dissolved contamination. In this incident, the contaminant is shown to spread over a large area because of the proximity of the source to the Kuroshio Current.

\section{Introduction}

On 6 January 2018, the Iranian oil tanker Sanchi collided with a freighter named CF Crystal in the East China Sea (ECS) at $30^{\circ} 42^{\prime} \mathrm{N}, 124^{\circ} 56^{\prime} \mathrm{E}$ (pink dot, Figure 1) - just about $300 \mathrm{~km}$ away from the City of Shanghai, one of the largest metropolitan centers in the world. The incident resulted in the tragic loss of Sanchi's entire crew of 32 and exposed the economically vital ECS to a potentially severe environmental threat from Sanchi's cargo of 136,000 tons of natural gas condensates (NGC) and more than 2,000 tons of heavier bunker oil. The tanker drifted ablaze for 8 days and subsequently sunk, on 14 January, near the edge of ECS shelf at about $28^{\circ} 22^{\prime} \mathrm{N}, 125^{\circ} 55^{\prime} \mathrm{E}$ (red rhombus, Figure 1). To this date, it remains unknown how much condensates remained in the tanker when it capsized and what have happened to those remaining condensates. Resting on the seafloor at about $110 \mathrm{~m}$ beneath the sea surface, the unburned condensates and bunker oil, if leaked, may pose an environmental risk to the marine environment in the ECS and beyond. 


\section{(3)}

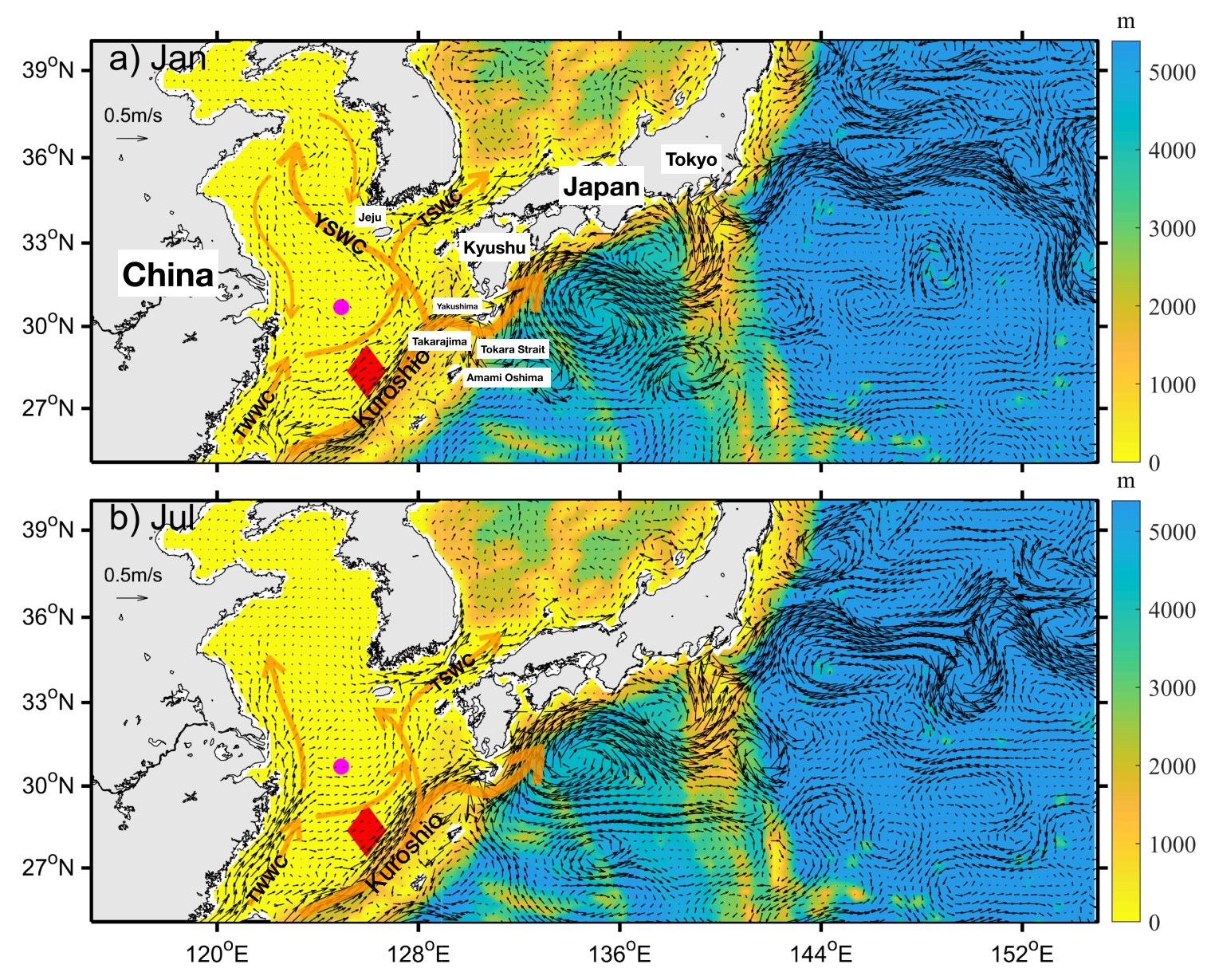

Figure 1. The depth-averaged (from surface to $380.21 \mathrm{~m}$ ) velocity in (a) January and (b) July of 2018 (velocity vectors are truncated at $50 \mathrm{~cm} / \mathrm{s}$ ). The bold arrows indicate the main currents in this area. The background color denotes depths in meters. The red rhombus indicates the location of the sunken tanker, and the magenta dot is where the collision took place.

Despite the massive scale of the spill, the public angst receded soon after this incident mainly because the feared widespread pollutions, like what happened in Prince William Sound after the Exxon Valdez incident in 1989, did not happen after this incident. In fact, the spilled condensates seemed to have vanished within weeks. This incident is unprecedented because it was the first large maritime spill of the NGCs in history (all major maritime spills previously were involved with crude oil). Compared with crude oil, condensates are much more volatile and seldom last more than a few days on sea surface. Therefore, it has been postulated that the high volatilization may have spared ECS from what Prince William Sound went through almost 40 years ago. This optimism, however, may have overlooked one important factor-the relatively high aqueous solubility of condensate hydrocarbons.

A condensate is typically a mixture of hydrocarbon liquids of low-molecular weights. In contrast, the crude oil consists of mainly hydrocarbons of higher molecular weights that have much lower aqueous solubility. When spilled to the ocean, the crude oil tends to clump into black globules and oil slicks that could float on the sea surface for months, even years. The visual impact from a crude oil spill is always profound even to the naked eye. Although condensates are much more volatile than crude oil, they are, however, much more soluble in seawater especially for those components with lower carbon numbers. The aqueous dissolution can be further enhanced if the leakage is from an underwater source such as from the sunken Sanchi at a depth of $110 \mathrm{~m}$. Reddy et al. (2012), for instance, observed deep plumes that were enriched with dissolved hydrocarbons near the site of the Deepwater Horizon oil spill.

Once dissolved in seawater, hydrocarbons are degraded mainly through microbiological processes. The efficiency of biodegradation depends on many factors, and chief among them is the population density of 
the right types of microbes that consume condensate hydrocarbons for energy. Other factors, such as temperature, oxygen, and nutrients also affect the biodegradation effectiveness. In terms of environmental risk, it is worth noting that the higher-solubility hydrocarbons with lower molecular weights are often more toxic for aqueous environments (e.g., ConocoPhillips Barossa Project, 2017).

An ideal assessment for the dispersion of condensate-contaminated water in this incident would be conducted through comprehensive observations. The time window for such an opportunity, however, has already closed due to a lack of coordinated observations. The remaining alternative is model-based assessments that would inevitably rely on some ad hoc assumptions. In this study we assume that a bottom layer of hydrocarbon-enriched water is formed in the vicinity of the sunken tanker due to the underwater leakage of condensates that remained in the tanker. We then construct a model to assess how this body of contaminated water would be spread by advection and diffusion and depleted by volatilization and biodegradation. Most previous modeling studies dealt with spills of crude oil that is often treated as insoluble Lagrangian parcels. We formulate our model to reflect that NGCs are highly volatile and have relatively high solubility in seawater. Without any guidance from observations, model assessments, including the present one, are likely to have many uncertainties. The main purpose here is not to provide a quantitative assessment but rather to illustrate the hidden risk from the dissolved hydrocarbons and their lasting impacts. The three-dimensional advection is computed by using the velocity field from a high-resolution ocean general circulation model. The diffusion, biodegradation, and volatilization are represented in the model with some simple parameterizations. We have tested various scenarios with large ranges of parameters. It is found that dissolved hydrocarbons may spread far away from the sunken site even with very high volatilization and biodegradation.

The paper is organized as follows. Section 2 describes some background information that is relevant to this study. The regional circulation, which predominantly affects the dispersion of the contaminant, is discussed in section 3. In section 4 we introduce the model of condensate dispersion and discuss the parameterizations of key processes. The results from the control run and some additional experiments are shown in section 5 . Section 6 summarizes our results and draws conclusions.

\section{Background}

\subsection{Aqueous Dissolution of NGC Components}

Hydrocarbons in NGC mostly fall within a carbon range between C2 and C30 (Environment Canada, Health Canada, 2016). Their densities are considerably lower than that of the seawater, and therefore, condensates tend to float as a thin layer on the sea surface. Three weathering processes, that is, dissolution in water, volatilization, and biodegradation, effectively deplete the more soluble, volatile, and degradable components and leave those more weathering-resistant compounds, typically with higher-molecular weights, in residues.

The weathering processes can be affected by dynamical processes in the ocean. The vertical mixing and upwelling/downwelling, for instance, would redistribute the dissolved hydrocarbons over the water columns and affect their resident times in subsurface water before exposure to evaporation on the sea surface. Since low molecular weight hydrocarbons are both more soluble in seawater and more volatile, it is expected that the most soluble components will still be lost primarily by volatilization because it occurs 10 to 1,000 times faster than dissolution (Lee et al., 1990). Harrison et al. (1975) determined that the dissolution rate may be as low as $1 \%$ of the volatilization rate. Thus, only a small proportion of the soluble components will be dissolved in the water (CONCAWE (Conservation of Clean Air and Water in Europe), 1983; API (American Petroleum Institute), 2010, available from: http://www.petroleumhpv.org/petroleum-substances-and-categories/kerosene-jet-fuel; Lee et al., 1990). The degree of volatilization is primarily dependent on the volatilities of the components of the petroleum mixture, along with other environmental conditions such as temperature, wind, and water conditions if spilled into water (CONCAWE 1983). Virtually all carbons lower than $\mathrm{C} 12$, such as BTEX, have been found to volatilize from water within 24 hr (RMRI (Risk Management Research Institute), 2007; NRC (National Research Council), 2003).

Previous assessments of volatilization versus dissolution in weathering processes were made mostly in controlled and confined environments, such as water pools or tanks, with condensates being released to water surface. The situation for the Sanchi incident differs considerably from such scenarios. First, the ocean is much more turbulent in terms of mixing than a thin layer of water in a pool. The dissolution of a 
substance in water can be much enhanced by mixing processes. Second, if the condensates are released to the ocean at the depth of $110 \mathrm{~m}$ in the current case as opposed to leakage onto the sea surface, the leaked condensates would have to go through dissolution processes before evaporation becomes effective on the sea surface. The underwater leakage could form bottom plumes with water enriched with dissolved hydrocarbons, a scenario similar to the phenomenon that was observed in the Gulf of Mexico near the site of Deepwater Horizon (Reddy et al., 2012). The dissolved hydrocarbons in an underwater plume are more insulated from the surface evaporation and therefore may have longer resident times in the ocean.

It is useful to have quantitative information of the hydrocarbon composition in order to assess the aqueous solubility of condensates in the Sanchi incident. Different hydrocarbon components in NGCs, typically between $\mathrm{C} 2$ and $\mathrm{C} 30$, have vastly different aqueous solubilities, ranging from very low $(0.0004 \mathrm{mg} / \mathrm{L})$ for tetradecyl-benzene $(\mathrm{C} 20)$ to very high $(1,790 \mathrm{mg} / \mathrm{L})$ for the simplest monoaromatic structure (C6, benzene) (Environment Canada, Health Canada, 2016). Any condensate is a mixture of various hydrocarbons, and its solubility is often dominated by the solubilities of a few low carbon number components. For instance, S. L. Ross Environmental Research Ltd. (1982) estimated that four components, that is, benzene, toluene, ethylbenzene, and xylenes, contribute to $91 \%$ of the solubility of Venture condensate. Unfortunately, little is known about the composition of NGCs in Sanchi. It is known, however, that the cargo was from Iran's South Pars.

Hydrocarbons in the South Pars are reservoired in Jurassic, Cretaceous, and early Miocene carbonates that generally consist of pelletal, oolitic or bioclastic grainstones, and reefal limestones (Rabbani \& Kamali, 2005). The South Pars condensate has a density of about $0.72-0.74 \mathrm{~g} / \mathrm{cm} 3$ at the temperature of $20{ }^{\circ} \mathrm{C}$ and a viscosity of about $0.6958 \mathrm{~mm} 2 / \mathrm{s}$ at $50{ }^{\circ} \mathrm{C}$ (Wang et al., 2012; Zhou, 2012). The condensate from the region is also known to have high contents of poisonous gases such as hydrogen sulfide and mercaptan sulfur (Ling, 2013; Tan, 2012).

Galimov and Rabbani (2001) analyzed the isotopic geochemical characteristics of natural gases and condensates from several sources in South Pars and found that the isotopic compositions of condensates are overall similar. Distribution of n-alkanes in South Pars condensates shows the dominance of C5 to C10. The condensate from the Kangan Formation, for instance, has particular high content of C6 and C7, almost 20\% each (Figure 8 of Galimov \& Rabbani, 2001). Some outliers have also been identified. The condensates from the Dalan Formation, on the other hand, have high concentration levels over a broader range of hydrocarbons from $\mathrm{C} 5$ to $\mathrm{C} 12$, with the relative content from each of them in the range between $8 \%$ and $12 \%$.

The aqueous solubility decreases rapidly toward higher molecular weight hydrocarbons. All main hydrocarbons from the South Pars are dominated by C5-C12, which are highly soluble in seawater (see the Physical and Chemical Data Tables for NGCs, Appendix C, Environment Canada, Health Canada, 2016). Therefore, it is plausible to assume that the water column in the vicinity of the sunken tanker would be enriched by hydrocarbons with concentration level tilted toward lower molecular weight components such as C5 and C6.

\subsection{Quantity and Leakage Rate}

A major unknown for this study is the rate and duration of leakage from the sunken ship. No effort has been made, at least not publicly known, to quantify such information. Opportunities to gather such important information may have already been lost. Our assessment model is linear and treats NGCs as passive tracers (meaning no feedback to dynamical processes), so the leakage rate affects only the magnitude (linearly) not the pattern of the condensate dispersion. In this study, we test two scenarios, one assuming that the leakage is held steady over the period of simulation, which ends on 31 January 2019, and another specifying that the leakage decreases exponentially with time.

\subsection{Microbiological Degradation}

Dissolved hydrocarbons are consumed by certain types of microbes. The most important factor is the population density of condensate-consuming microbes in the region. Other factors are like oxygen supply, certain types of nutrients, and water temperature. In general, biodegradation is more effective under aerobic conditions. Previous studies indicate that the biodegradation of fossil fuel hydrocarbons in seawater would take as short as a few months to as long as years (Slater et al., 2006). In our model we parameterize the microbiological degradation by using a linear damping on the condensate concentration. It is a highly simplified parameterization given the complexity of microbiological processes. 


\subsection{Advection and Mixing}

The fourth factor to be considered is the advection and mixing of the NGCs in the ocean. In our model, we use the daily oceanic velocity field from Global Ocean Sea Physical Analysis and Forecasting Products distributed by CMEMS (http://marine.copernicus.eu/services-portfolio/access-to-products/?option=com csw\&view=details\&product_id=GLOBAL_ANALYSIS_FORECAST_PHY_001_024) to compute the threedimensional advection of dissolved condensates. Turbulent mixing by mesoscale and submesoscale processes will be parameterized in the form of diffusion, a common method to parameterize diffusion of a tracer in ocean models.

\subsection{Previous Studies Related to the Sanchi Incident}

We would like to point out that even though the public interest in this incident has faded, there remains a strong interest in the science community to predict the scale, pace, and severity of the spreading and impact from this spill. There are at least two groups of oceanographers, China's First Institute of Oceanography (FIO) (Yin et al., 2018) and the UK's National Oceanographic Center (NOC) (https://noc.ac.uk/news/ coral-reefs-may-be-risk-sanchi-oil-tanker-contamination), who have conducted model-based predictions for the dispersion of the NGC from the Sanchi incident using the Lagrangian particle tracking method. The contaminated water is treated as a large sum of particles, like a large bucket of ping pong balls that are released at the site of the capsized tanker. The particles are dispersed by advection using the velocity fields from numerical models. Such a method emphasizes the advection. In contrast, the present model includes the effect of volatilization, biodegradation, and diffusion even though such processes are parameterized with considerable uncertainties. A more complete assessment will need to involve observations and a more sophisticated physical-biogeochemical model. This is beyond the scope of the present study. We will explore several scenarios such as various levels of biodegradation efficiencies or evaporation rates. We hope that our scenario-dependent assessments provide a better understanding of likely pathways, the pace of dispersion along each pathway, and the sensitivity of the contamination level to various factors, and so forth. Such information is useful for planning observation-based assessments.

\section{Regional Circulation}

We use the daily oceanic velocity field from Global Ocean Sea Physical Analysis and Forecasting Products distributed by CMEMS - a daily global ocean analyses system with a $(1 / 12)^{\circ}$ resolution simulation based on the NEMO 3.1 model. This model is based on Mercator projection and tri-polar ORCA grid type (Madec \& Imbard, 1996). It has 50 vertical levels with grid size $\Delta z$ ranging from about $1 \mathrm{~m}$ at the surface to about $450 \mathrm{~m}$ resolution at the bottom of the deep ocean. We use a model domain from $25^{\circ} \mathrm{N}$ to $40^{\circ} \mathrm{N}$ meridionally and from $115^{\circ} \mathrm{E}$ to $155^{\circ} \mathrm{E}$ zonally and from the surface to $1,062.44 \mathrm{~m}$ (upper 36 layers) vertically, approximately the depth of thermocline for the North Pacific Subtropical Gyre (e.g., Qu, 2002). As we will show the dissolved hydrocarbons are confined in the upper $400 \mathrm{~m}$ in all of our simulations. Using more layers has little effect on the results. It is interesting to note that the depth of the tanker's location is 110 $\mathrm{m}$, which is almost identical to the depth of the $23^{\text {rd }}$ level in the model ( 109.79 $\left.\mathrm{m}\right)$. Our simulation period is between 14 January 2018 and 31 January 2019.

The atmospheric forcing in the region is dominated by the Asian Monsoon. In winter months a strong northerly wind with cold and dry air enhances the surface heat flux and results in strong vertical mixing over the whole water column on shelves. Figure 1 shows the monthly mean and depth-averaged (0-380 m) velocity for January and June 2018, respectively. The bold arrows indicate major currents in the region. The tanker is located at $28^{\circ} 22^{\prime} \mathrm{N}, 125^{\circ} 55^{\prime} \mathrm{E}$ where major currents intertwine. Less than $50 \mathrm{~km}$ to the east, the mighty Kuroshio Current - the western boundary current (WBC) of the North Pacific Subtropical Gyre flows northward along the continental slope toward the east coast of Japan. On the ECS shelves, there is a complex ECS shelf circulation system that is forced by the seasonally varying monsoonal wind, influenced by the Kuroshio, constrained by bathymetry, and dynamically connected with circulations in the South China Sea through the Taiwan Warm Current and in the Japan/East Sea through the Tsushima Warm Current (TSWC; Lie \& Cho, 1994; Ma et al., 2010). The oceanic currents in the vicinity of the tanker are generally northeastward in all seasons (Figure 1). The northward shelf currents join the intrusion of Kuroshio water to form the Tsushima Warm Current that enters the Japan Sea. But in the winter season, a portion of the northward transport from both shelf flow and Kuroshio enters the Yellow Sea Trough and forms a 
northward flow, the Yellow Sea Warm Current (YSWC), toward China (Lie \& Cho, 2002; Lie et al., 2009; Lin et al., 2011; Lin \& Yang, 2011; Uda, 1934, 1935). From the velocity field shown in Figure 1, there are three potential pathways for the condensate dispersion: along the Kuroshio to the east coast of Japan, through the TSWC into the Japan Sea, or toward China's coast via the YSWC. The spread of contaminants along each possible pathway, however, is influenced by not only the advection but also biodegradation, surface evaporation, and mixing in the ocean.

\section{The Formulation of a Simple Model for NGC Dispersion}

All major maritime spills previously were involved with crude oil that typically has high viscosity, low evaporation rate, and low solubility in seawater. The insoluble crude oil globules are often treated as Lagrangian particles in models (e.g., Huntley et al., 2011; Wang et al., 2005). The NGCs, however, are highly volatile, and their lower molecular weight hydrocarbons have relatively high aqueous solubilities. The dissolved hydrocarbons should be treated more appropriately as tracers that are dispersed by mixing and advection and depleted by biodegradation and volatilization. Here we formulate a simple advection-diffusion model with some simple representations for biodegradation and volatilization.

In our model we prescribe a single-point source of condensate flux into the ocean at the $110 \mathrm{~m}$ depth at Sanchi's location. We conducted simulations by prescribing the flux as being either steady or gradually decreasing over the simulation period. The concentration of the dissolved condensate $Q(x, y, t)$ is governed by advection, diffusion, and a damping that grossly represents the condensate degradation. The surface evaporation is treated as a surface boundary condition for the vertical flux term, similar to what is commonly used in numerical models for air-sea fluxes of heat or gases. The model equation is

$$
\frac{\partial Q}{\partial t}+u \frac{\partial Q}{\partial x}+v \frac{\partial Q}{y}+w \frac{\partial Q}{\partial z}=K_{h}\left(\frac{\partial^{2} Q}{\partial x^{2}}+\frac{\partial^{2} Q}{\partial y^{2}}\right)+K_{v} \frac{\partial^{2} Q}{\partial z^{2}}-\lambda Q
$$

where the first two terms on the right-hand side of (1) are the horizontal and vertical turbulent diffusion, respectively, and $-\lambda Q$ presents the removal of dissolved condensate through biological degradation. We specify a point source for the leakage at the wreckage site and assume that the water mass within a radius of $46 \mathrm{~km}$ (five model grids) in the bottom two layers (the $22^{\text {nd }}$ and $21^{\text {st }}$ model layers at the leakage site) is saturated with dissolved condensates initially (i.e., $Q=1$ ) and then changes with time $F(t)$, where $F(t)$ is a function that will be specified in each simulation scenario. Outside this small volume of water the concentration $Q$ is modeled according to equation (1):

$$
Q x, y, z, t= \begin{cases}F t & \text { if } r \leq r_{0} \text { and in the 21st and 22nd layers } \\ \text { modeled by } 1 & \text { otherwise }\end{cases}
$$

where $r=\sqrt{\left(x-x_{0}\right)^{2}+\left(y-y_{0}\right)^{2}}$ is the distance from the sunken tanker's position $\left(x_{0}, y_{0}\right)$ and $r_{0}=46 \mathrm{~km}$ is the radius of a circular area within which the leaked condensate is assumed to be dissolved into the water saturated. The horizontal velocity components $(u, v)$ are from the CMEMS Global Ocean Sea Physical Analysis and Forecasting Products' daily data set. The model output provides only the horizontal velocity component. The vertical velocity component is estimated from the continuity equation for incompressible fluid, that is, $u_{x}+v_{y}+w_{z}=0$. Biodegradation time scale is $1 / \lambda$, which may range from months to years (Slater et al., 2006) depending on the population density of the right kind of microbes and local environmental conditions for such microbes.

In the surface layer the dissolved hydrocarbons are exposed to the atmosphere and, therefore, are available for evaporation. This process is treated as the upper boundary condition for the vertical diffusion, a commonly used method in treating fluxes of heat and gases in models, that is,

$$
K_{v} \frac{\partial Q}{\partial z}=-\gamma Q \quad \text { at } z=0
$$

Because the concentration of the dissolved condensate, $Q$, is always greater than or equal to zero, the evaporative flux at the air-sea interface is always upward. The magnitude of the evaporation is assumed to 
be proportional to the concentration in layer one (surface layer). The coefficient $\gamma$ is determined by a number of factors including the volatilities of hydrocarbons in the water and surface wind speed, and so forth. As we will show later, the value of $\gamma$ affects $Q$ only mildly over the water column except in the surface layer.

\section{Results}

We would like to emphasize again that the parameters for the biodegradation and evaporative coefficients, $\lambda$ and $\gamma$, are not well quantified. We have explored the model sensitivities to these parameters, and the result will be presented and discussed.

\subsection{Control Run}

In the first experiment ("control run"), we assume a steady leakage from the sunken tanker and therefore set $F(t)=1$ in equation (2). We also choose the $e$-folding time scale for biodegradation to be 30 days, that is, $\lambda=1 /(30$ days $) \approx 1.16 \times 10^{-7} \mathrm{~s}^{-1}$. The efficiency of biodegradation depends on many factors, and some previous studies indicate that it typically takes months to years for microbes to consume dissolved hydrocarbons. The value of $\lambda$ used in the control run, therefore, reflects a scenario of aggressive degradation process. Among all model coefficients, $\lambda$ has the greatest impact on the distribution of $Q$. Results from additional experiments will be presented to illustrate this impact. We set $K_{h}=500 \mathrm{~m}^{2} / \mathrm{s}$ and $K_{v}=10^{-4} \mathrm{~m}^{2} / \mathrm{s}$; both are moderate and within the range of what are typically used in the modeling community. We use an evaporative time scale of 2 days for a thickness of $1 \mathrm{~m}$ (which is the first layer's grid size), that is, $=\frac{\Delta z_{1}}{2 \text { days }}$, where $\Delta z_{1}=1 \mathrm{~m}$ is the surface layer's grid size. This is consistent with previous assessments that NGC would be volatilized within days when present on the water surface.

As described in equation (2) the water is assumed to be directly polluted by the leaked condensates within the bottom two layers $\left(21^{\text {st }}\right.$ and $\left.22^{\text {nd }}\right)$ in a small circular area with a radius of $46 \mathrm{~km}$ around the sunken tanker. Outside this small area, the contaminants are dispersed three-dimensionally by advection and diffusion and depleted by biodegradation and volatilization. The polluted water may flow across the shelf break to the deep open ocean or intrude shoreward toward coasts. Due to the three-dimensional nature of all processes, the concentration of dissolved condensates is expected to vary greatly with depth at a given location, especially in the deep open ocean. To better estimate the net dispersion rate, we compute the integrated content $P(x, y, t)$ a depth $z_{b}$ to sea surface:

$$
P(x, y, t)=\int_{z=z_{b}}^{\text {surface }} Q(x, y, z, t) \mathrm{d} z
$$

As described in section 3 we are using the upper 36 layers in the upper 1,062 $\mathrm{m}$ in our simulations. The dissolved condensates in all our simulations are confined in the upper $500 \mathrm{~m}$. In (4) the depth $z b$ for vertical integration is set to be $1,062 \mathrm{~m}$ in deep ocean or the depth of the seafloor wherever the water is shallower than $1,062 \mathrm{~m}$. To compare with the content at the site of wreckage, we will introduce a new variable $q(x, y, t)=P(x, y, t) / P_{0}$, which is the ratio between $P$ and the initial content $P_{0}$ at tanker's location, that is, $\left(x_{0}, y_{0}\right)=\left(125^{\circ} 55^{\prime} \mathrm{E}, 28^{\circ} 22^{\prime} \mathrm{N}\right)$. The initial content is

$$
P_{0}=\int_{z=\text { bottom }}^{\text {surface }} Q\left(x_{0}, y_{0}, z, t=0\right) \mathrm{d} z
$$

Note that $P_{0}$ is integrated from the bottom, which is $109 \mathrm{~m}$ in the model. The variable $q(x, y, t)$ measures the instantaneous depth-integrated content at location $(x, y)$ in the model domain relative to the initial content at the leakage site.

The ocean currents in this region are strongly influenced by the bathymetry. The flow along the shelf break near the tanker's location is mainly parallel to the Kuroshio, and they merge near the entrance of the Yellow Sea Trough (YST) (Figure 1, note that the velocity vectors are truncated at $50 \mathrm{~cm} / \mathrm{s}$ ). There is a considerable onshore intrusion of the Kuroshio water toward the Bohai-the northern ECS area between China and Korea. In winter months, this onshore transport bifurcates to two branches- the YSWC along the YST toward the China's coast and the TSWC that turns northeastward into the Japan Sea (Lie \& Cho, 1994; Beardsley et al., 1985; Fang et al., 1991). They are referred to as warm currents because they carry Kuroshio Current waters that are considerably warmer than the ECS shelf water in winter months. As we 


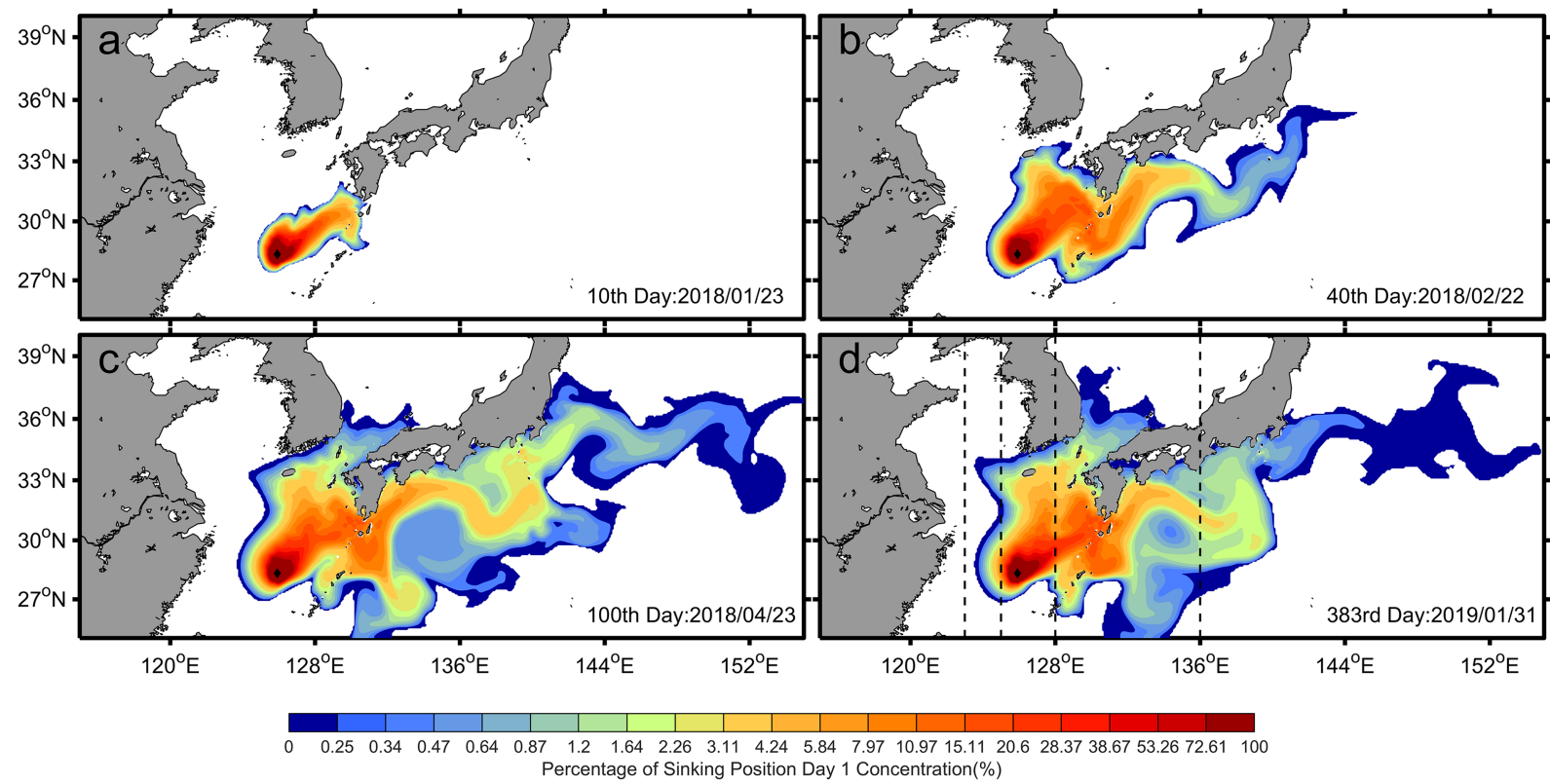

Figure 2. The distribution of $q(x, y, t)$ in the control run with $K_{h}=500 \mathrm{~m}^{2} / \mathrm{s}, \mathrm{K}_{\mathrm{v}}=10^{-4} \mathrm{~m}^{2} / \mathrm{s}, \lambda=1 /\left(30\right.$ days), and $\gamma=1 /\left(2\right.$ days) on (a) $10^{\text {th }}$ day, (b) $40^{\text {th }}$ day, (c) $100^{\text {th }}$ day, and (d) $383^{\text {rd }}$ day. The black rhombus marks the location of the sunken Sanchi. Area with concentration under $0.1 \%$ is neglected. (The unit of $q$ is percentage, i.e., $q=100 \%$ when $P=P_{0}$ ).

will discuss further, the Kuroshio Current, TSWC, and YSWC, indicated by orange arrows in Figure 1, are three major potential conduits for dispersing the condensate-contaminated water.

The control run is integrated over 383 days from 14 January 2018-the date that Sanchi capsized-to 31 January 2019. Figure 2 shows snapshots of $q(x, y, t)$ at the end of the $10^{\text {th }}$ (23 January 2018), $40^{\text {th }}$ (22 February 2018), $100^{\text {th }}$ (23 April 2018), and $383^{\text {rd }}$ (31 January 2019) model day, respectively. The contaminant water is advected initially along the shelf edge and subsequently mixed with Kuroshio Current water when two currents merge at the entrance of YST. Once into the Kuroshio, it enters the fast track because the Kuroshio is a WBC and among the swiftest currents in the world's ocean. In fact, it reaches the coast of Kyushu in the southern Japan, about 300-400 km away from the source, in only about10 days (Figure 2a), indicating the averaged velocity of $35-50 \mathrm{~cm} / \mathrm{s}$ over this 10 day period. In this initial 10 day period, the dissolved condensate components have spread only over a small area.

About 1 month later on 22 February 2018 (the $40^{\text {th }}$ model day) the contaminated water has spread further downstream along the Kuroshio pathway, reaching as far north as $36^{\circ} \mathrm{N}$ off Japan's east coast (Figure 2b). The coast of Tokyo would have been impacted by the arrival of the contaminant. The distribution of $q(x, y$, $t$ ) clearly resembles that Kuroshio pathway. For instance, the Kuroshio flows out of the ECS through Tokara Strait between Amami Oshima and the southern Kyushu (Qiu et al., 1990; Yang et al., 2012; Lie \& Cho, 2016) where the contamination level is particularly high. This is consistent with the news report that an oil slick was found on the shores of Takarajima Island - an island between Amami-Oshima and Yakushima on 28 January (https://www.reuters.com/article/us-china-shipping-accident/oil-from-sunkeniran-tanker-reached-japan-shores-coast-guard-idUSKCN1G601O). Meanwhile, a large area around Jeju is affected considerably by this date. The distribution on the $40^{\text {th }}$ day already indicates that the advection of dissolved condensates tends to bifurcate into two main directions: One is following the Kuroshio mainstream northeastwardly along Japan's east coast; another is flowing toward the Tsushima Strait—-the entrance to the Japan Sea.

The contaminated water has spread further into the spring. On the $100^{\text {th }}$ day on 23 April 2018, it not only covers the east coast of Japan but also extends eastward into the Pacific Ocean interior along the Kuroshio extension (Figure 2c). Instead of spreading as a straight jet, the contaminated water is transported along the meandering Kuroshio Extension (Ma et al., 2015; Qiu \& Chen, 2005, 2010), which, according to 
analyses of altimetry data, is among the most dynamically variable regions on the intraseasonal and seasonal time scales (Chao \& Fu, 1995). On the ECS shelves, the contaminated waters have intruded into the Japan Sea through the Tsushima Strait, extending to the eastern boundary of Korean Peninsula and the western coast of Japan. The condensate content is particularly high in the triangle-shaped area between the sunken tanker, Jeju Island, and Kyushu and also along the tail of the Kuroshio Current and its extension. The overall pattern resembles a fantail goldfish with its head and eyes at the tanker's location. The "fantail" is spread much broader along the main tail—the Kuroshio Extension.

Besides these two pathways (i.e., along the Kuroshio Current to Japan's east coast and through the TSWC into the Japan Sea), one interesting feature in Figure 2 is the northwestward intrusion along the Yellow Sea Trough. Initially, the contaminated water appears to have moved northwestward along the YSWC as shown in Figures 2a and 2b. The intrusion along the YST, however, stalled in the spring. In comparison, the contaminated water has continued, albeit slowly, to penetrate into the Japan Sea. The difference is attributable to the different seasonal variability of these two currents. The YSWC, as shown in Figure 1, is highly seasonal. The velocity along the YST is weak or even absent except in the winter months when a northward current, the YSWC, is forced by the northerly wind stress (Hsueh et al., 1986; Hsueh, 1988; Lin \& Yang, 2011; Lin et al., 2011; Tak et al., 2016). The YSWC would be weak, if still present, in late April-100 days after the submersion of Sanchi. Consequently, the intrusion of the contaminated water into Yellow Sea along the YSWC would have been halted by then. The TSWC from the ECS to the Japan Sea, on the other hand, is a perennial current. It actually strengthens in the spring when the winter monsoon is transitioning to a summer monsoon (e.g., Kida et al., 2016; Ma et al., 2010, 2012; Takikawa et al., 2005). After the condensatecontaminated water enters the Japan Sea, it bifurcates into two branches, one along Korea's east coast and another along Japan's west coast (Katoh, 1994; Cho \& Kim, 2000; Teague et al., 2005). The condensate-contaminated water has spread further inside the Japan Sea, especially along Japan's west coast on the $100^{\text {th }}$ model day (Figure 2c). Its concentration has also increased considerably along the Kuroshio Current off Japan's east coast.

On the $383^{\text {rd }}$ model day, which is 31 January 2019 and final day in our simulation, the distribution and magnitude of the dissolved condensates are actually similar to that on the $100^{\text {th }}$ day. If the oceanic currents were held steady, there would be an equilibrium state in which the advective and diffusive fluxes (sources) are balanced by the depletion processes (sinks). After reaching such an equilibrium state, the polluted area would stop further expanding even if the leakage source remains active. The overall similarity between Figures $2 \mathrm{c}$ and $2 \mathrm{~d}$ indicates that the time scale for reaching such an equilibrium state is likely shorter than 100 days.

In addition to the horizontal distribution shown in Figure 2, it would be interesting to examine the contaminant's vertical distribution. Since the condensate is leaked from the sunken vessel on the seafloor at $110 \mathrm{~m}$, the concentration dissolved hydrocarbons, as expected, would be bottom intensified at the site. We plot four meridional sections on 31 January 2019 - the last day of the model integration along $123^{\circ} \mathrm{E}, 125^{\circ} \mathrm{E}, 128^{\circ} \mathrm{E}$, and $136^{\circ} \mathrm{E}$, respectively (Figure 3). The concentration $Q(x, y, z)$ is low along $123^{\circ} \mathrm{E}$ (Figure $3 \mathrm{a}$ ), which is located to the west of the tanker. This is due to the fact that the YSWC, which is the main mechanism for the westward advection, is weak or reversed from spring to fall. Slightly to the east, the $125^{\circ} \mathrm{E}$ section cuts across the intrusion branch through the entrance of Yellow Sea (Figure 3b). There are two centers of elevated $Q$ : The northern one around $33^{\circ} \mathrm{N}$ is at the entrance of the Yellow Sea Trough, and the southern one near $29^{\circ}$ $\mathrm{N}$ is located just to the west of the sunken vessel. In the northern center near $33^{\circ} \mathrm{N}$ the core of the contaminant water is in the middepth between surface and seafloor. We speculate that this is due to the fact that the water mass in the YSWC in the winter has two sources- the upper layer is derived from the northward flow shelf current that carries the contaminant water and the low layer originates from saltier and denser water from the Kuroshio Current that was not contaminated. The evaporation effectively lowers the surface concentration and results in a maximum core in the subsurface layer. In the southern center around $29^{\circ} \mathrm{N}$, the plume of contaminant is clearly bottom intensified indicating that lateral advection and diffusion dominant over vertical processes in this region. The distribution suggests that sampling of surface water even at or near the site of the sunken tanker would be insufficient to detect the level of dissolved hydrocarbons. One has to measure the concentration over the whole water column.

Now let us examine the distribution along $128^{\circ} \mathrm{E}$ - on the eastern side of the ship wreckage (Figure 3c). Compared with the previous two sections on the western side, the content $Q$ is both significantly higher and also more broadly distributed, as a result of the Kuroshio Current. The high-content water along 


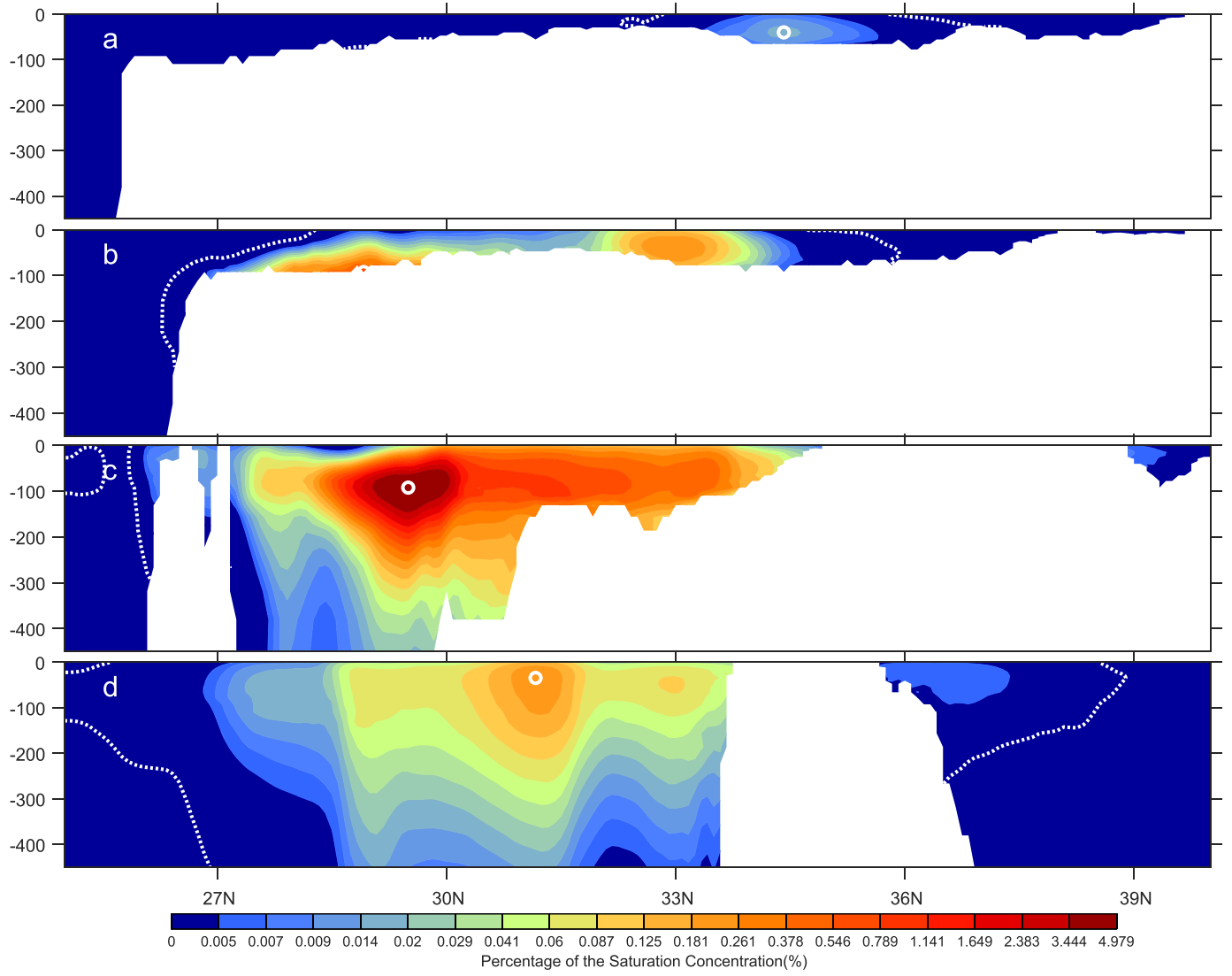

Figure 3. The vertical sections of concentration $Q(x, y, z)$ on 31 January 2019 along (a) $123^{\circ} \mathrm{E}$, (b) $125^{\circ} \mathrm{E}$, (c) $128^{\circ} \mathrm{E}$, and (d) $136^{\circ} \mathrm{E}$ (sections showed with black dash line in Figure 2d). The white circle indicates the location with highest concentration in each section. It is noted here that the dissolved condensates flow offshore as a subsurface plume. The surface concentration is low due to high eva $a_{\text {poration. }}$

section $128^{\circ} \mathrm{E}$ spreads from $28^{\circ} \mathrm{N}$ to about $34^{\circ} \mathrm{N}$. In horizontal, the contaminated water extends from the sinking latitude to the southern end of the Korean Peninsula. In vertical, the high value extends from the surface to as deep as about $300 \mathrm{~m}$ with the high value core at about 90-100 $\mathrm{m}$. It is interesting to note that the contaminant extends to the deep ocean as a subsurface plume mainly between the surface and $300-400 \mathrm{~m}$ depth. Further to the east along the "tail" section at $136^{\circ} \mathrm{E}$, the content is much diluted and the core of the plume is at about $35 \mathrm{~m}$. The broad dispersion and dilution are likely enhanced by meanders and eddies that are typically abundant in the Kuroshio Extension area. Overall, Figure 3 reveals that the highest concentration of the NGC is not located at the surface but the subsurface due the bottom source and surface evaporation.

How about the temporal evolution of the three-dimensional field of $Q$ ? We identify the position of the plume's core, which is defined as the position of maximum $q$ at each longitude, based on the distribution on 31 January 2019, the last day of the model simulation and 383 days after the tanker sank. The position is marked by the white points in Figure 4a. The evolution of the plume along this path is shown on the right panel in Figure 4 on the $10^{\text {th }}, 40^{\text {th }}, 100^{\text {th }}$, and $383^{\text {rd }}$ days after Sanchi capsized. The shelf break is located at about $127^{\circ} \mathrm{E}$ and is very close to the site of sunken tanker $\left(28^{\circ} 22^{\prime} \mathrm{N}, 125^{\circ} 55^{\prime} \mathrm{E}\right)$. Only in 10 days the plume has already moved across the shelf break into the deeper ocean in the subsurface layer and reached $130^{\circ} \mathrm{E}$. It continues to advance along the Kuroshio and reaches as far offshore as $134^{\circ} \mathrm{E}$ on the $40^{\text {th }}$ day. It is interesting to note that the plume seems to stop further spread along the Kuroshio after $40^{\text {th }}$ day. In fact, the distribution of $Q$ on the $100^{\text {th }}$ and $383^{\text {rd }}$ days is both similar to that on the $40^{\text {th }}$ day. This is consistent with what is shown in Figure 2. 


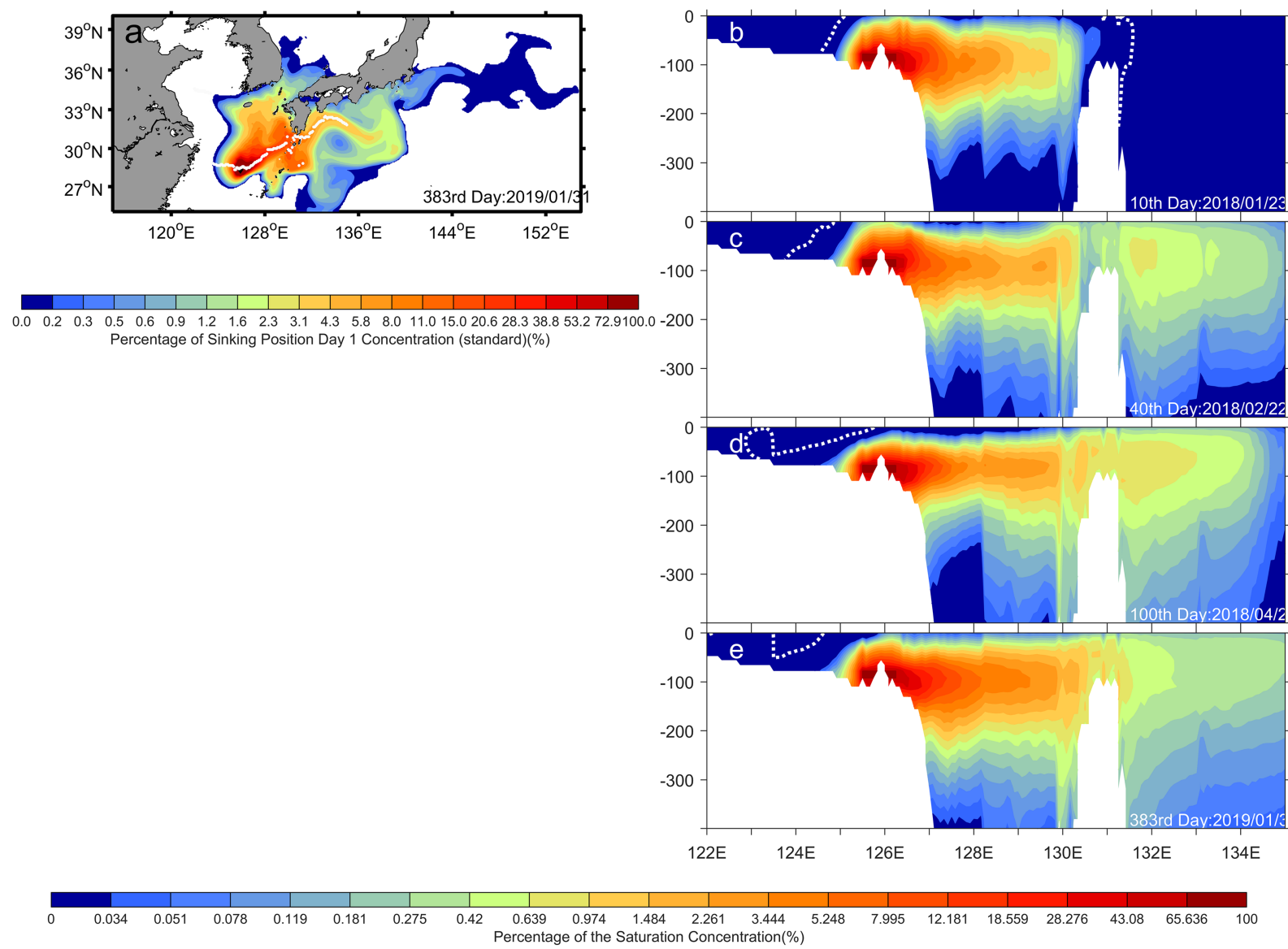

Figure 4. (a) The distribution of $q(x, y)$ on the $383^{\text {rd }}$ day (the figure is the same as Figure $2 \mathrm{~d}$ ). We use this $q(x, y)$ to define the axis of the core along the Kuroshio pathway, which is marked by white dots. The temporal evolution of the concentration $Q(x, y, z, t)$ along the core axis is shown on the right panel on four different dates, (b) $10^{\text {th }}$ day, (c) $40^{\text {th }}$ day, (d) $100^{\text {th }}$ day, and (e) $383^{\text {rd }}$ day.

The main feature in Figure 4 is that the contaminant water is spread as a plume beneath the surface, and the concentration in the surface layer is low due to the fact that condensates are highly volatile and their dissolved components would have evaporated in the surface layer. The contaminant water stays mainly as a subsurface layer because oceanic advection is mainly along isopycnal surfaces. Vertical velocity is mostly downward in the subtropical latitudes because of negative wind stress curl. Observational sampling strategies for future incidents should focus on the subsurface layers especially along the isopycnals originated from the leakages.

\subsection{Sensitivity of Biological-Damping Parameter}

Dissolved hydrocarbons in sea water are depleted through air-sea fluxes to the atmosphere and biodegradation by hydrocarbon-consuming microbes. The evaporation affects $Q$ mainly in the surface layer. In fact, we have tested several cases with different evaporation coefficient $\gamma$ in equation (3) and found that the subsurface distribution of $Q$ and the depth-integrated quantity $q$ are rather insensitive to this parameter (not shown). Our simulations indicate that the model distribution of $q$ is much more sensitive to the biodegradation coefficient $\lambda$. Biodegradation processes for condensates are complex and, to the best of our knowledge, not well quantified for this region. Therefore, we decided to conduct additional simulations to gauge model's sensitivity to $\lambda$.

In the control run shown in Figure 2, we use the value $\lambda=1 /(30$ days $)$ for the biodegradation coefficient. This reflects a scenario of a very aggressive degradation considered that the degradation process typically takes a few months to several years (Slater et al., 2006). Here we present results from four additional experiments with $1 / \lambda$ varying from 15 days to 365 days. In the first test we note that $\lambda=1 /(15$ days $)$ is unrealistically 


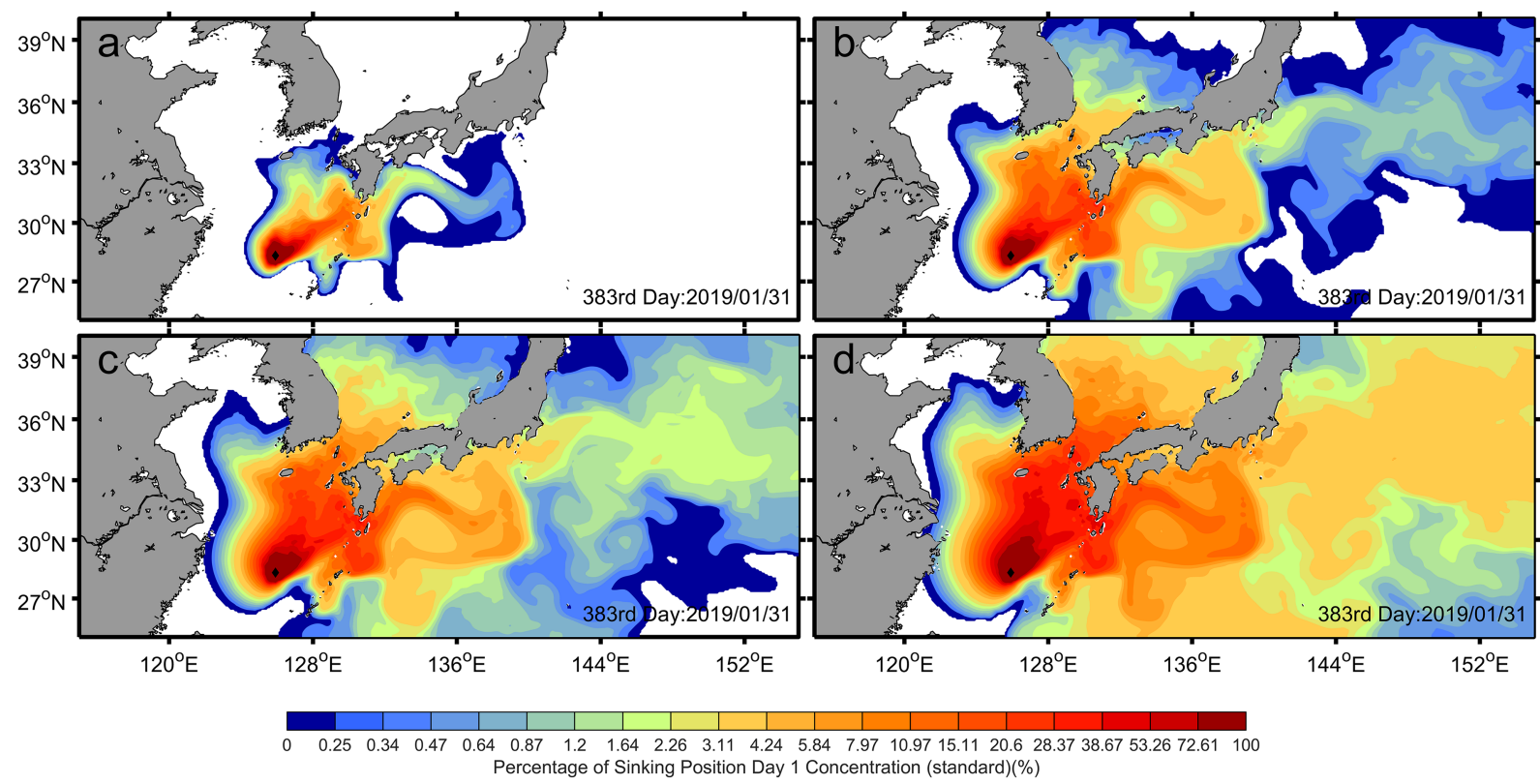

Figure 5. The distribution of $q(x, y)$ on 31 January 2019 (the $383^{\text {rd }}$ model day) for using four biodegradation coefficients that are different from the control run: (a) $\lambda=1 /(15$ days), (b) $\lambda=1 /(60$ days), (c) $\lambda=1 /(100$ days), and (d) $\lambda=1 /(365$ days). All other model parameters and forcing are the same as the control run. The spread of dissolved condensates is still significant even when biodegradation time scale is shortened to 15 days. It is worth noting that some previous studies indicate that the biodegradation time scales are between months to years. For such time scales, the scope and magnitude of the dissolved condensate content would be much higher than that in the control run.

short and the main purpose here is to test the model sensitivity. As in the control run case, we simulate the model for 383 days until 31 January 2019. Figure 5a shows that the area affected by the leaked condensate would be considerably shrunk compared with what is shown in Figure $2 \mathrm{~d}$ for the control run. The contaminated water, however, would still reach the southern coastline of Kyushu Island and the entrance of Yellow Sea Trough. The intrusion to Japan Sea is nearly absent. The comparison illuminates the sensitivity of this model to the biodegradation parameter $\lambda$.

In the next experiment we lengthen the $e$-folding degradation time scale to 60 day, that is, $\lambda=1 /(60$ days $)$, twice as long as that in the control run. In this scenario almost the whole model domain would have been affected by the contaminant water (Figure $5 \mathrm{~b}$ ). The affected area extends further northward along the Yellow Sea Trough. In the third experiment we further lengthen the biodegradation time scale to 100 days; both the affected area and the content level would have been further increased (Figure 5c). In fact, the almost whole domain east of $128^{\circ} \mathrm{E}$ is all covered by the contaminated water. Both coasts of Japan and the west coast of Korea are affected. It is worth noting that the pollution would touch China's coast near Shanghai in this scenario.

In the final run in this set of $\lambda$-sensitivity experiments we increase the $e$-folding time scale to 365 days. The magnitude and areal distribution of $q$ have greatly increased (Figure 5d). Even in the deep ocean to the east of Japan the depth-integrated content has reached as high as 3-4\% of that at the leakage site on the ECS. The area off China's coast and Korea's west coast is affected. It is worth noting that $=1 /(365$ days $)$ is still well within the range of the previously suggested range of months to years.

The comparison of these four additional experiments and the control run indicates that the model is highly sensitive to the biodegradation parameter. It suggests that any modeled assessments of this or future spills would have a large degree of uncertainty unless this parameter can be well quantified. It also indicates the importance of in situ measurements that would help quantify this important process.

\subsection{Scenarios of Collision Location}

The tanker drifted ablaze for 8 days and over $200 \mathrm{~km}$ after its collision on 6 January 2018 (Figure 1). Compared with where it capsized, the collision site is closer to China's coast but further away from the 


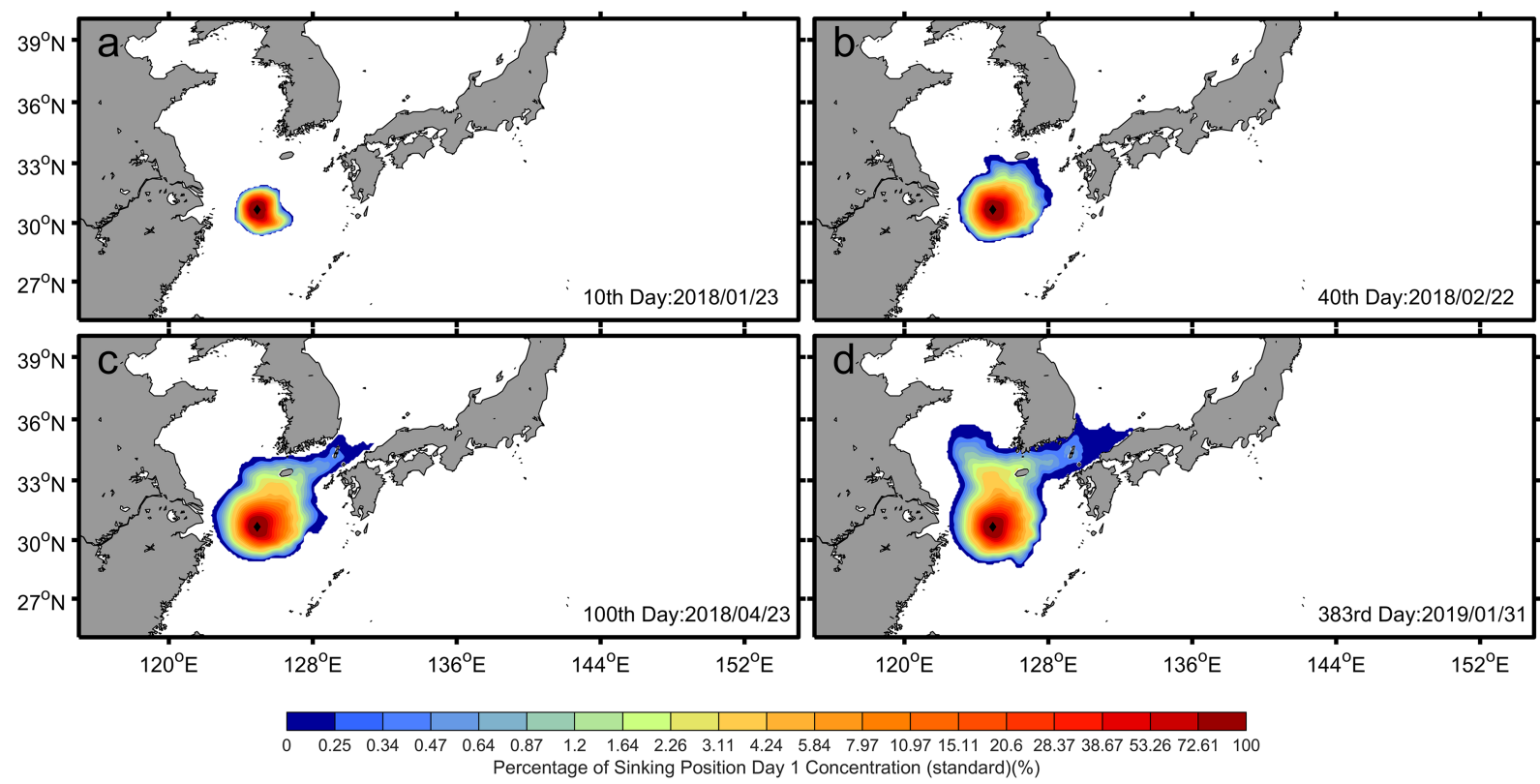

Figure 6. The distribution of $q(x, y, t)$ on a hypothetical scenario in which the tanker sank at the collision site, which is much closer to China's coast and further away from the Kuroshio Current than its actual sinking site. The model parameters are the same as the control run shown in Figure 2 except the location of the leakage. The affected area would be much smaller than that shown in Figure 2, and the east coast of Japan would have been spared from pollution. This supports our conclusion that the proximity of the leakage site to the Kuroshio Current makes the spreading far more effective.

Kuroshio Current. Did this 8 day and $200 \mathrm{~km}$ drift actually spare China's coastal water from pollution at the expense of Japan's east coast? To examine this, we design another experiment using the same model parameters as in the control run except that the leakage source is moved to the collision site $\left(30^{\circ} 42^{\prime} \mathrm{N}\right.$, $124^{\circ} 56^{\prime} \mathrm{E}$ ). Figure 6 shows that, unlike the previous cases, the contaminant water remains mostly on the ECS shelves, intruding along the Yellow Sea Trough and the Tsushima Strait. The leaked condensate never enters the Kuroshio Current, and therefore, the east coast of Japan would be spared from its pollution. It is interesting to note that the intrusion into the Japan Sea becomes considerably weaker than that in the control run. This is understandable because the TSWC derives its waters from both the Kuroshio Current and shelf water on the ECS. Without the Kuroshio route in the present case, the transport into the Japan Sea would have been weakened. It is also worth noting that the contaminant moves further upstream toward China's coast along the Yellow Sea Trough, most likely due to the proximity of the collision site to the trough. The Chinese coast, however, would still be not directly affected by this pollution even if the tanker capsulated at the collision.

\subsection{Sensitivity of Leaking Time}

In the control run, we assume the leakage to be steady in time. In reality, however, one would expect the leakage to decrease gradually and eventually shut off. In the next experiment, we specify that the leakage rate is held steady in the first 10 days and then starts to decrease exponentially from the eleven ${ }^{\text {th }}$ day forward with an $e$-folding time scale of 60 days. Specifically, we prescribe $F(t)$ in equation (2) as

$$
F(t)=\left\{\begin{array}{lr}
1 & \text { for } 0 \leq t \leq 10 \text { days } \\
e^{-(t-10) /(60 \text { days })} & \text { for } t>10 \text { days }
\end{array}\right.
$$

All other model parameters and parameterizations remain the same as in the control run.

Figure 7 shows the evolution of the dissolved condensate content on the $10^{\text {th }}, 40^{\text {th }}, 100^{\text {th }}$, and $383^{\text {rd }}$ days, respectively. The pattern in the first 100 days is similar to that in the control run shown in Figure 2 but with a smaller amplitude after 10 days. As the leakage decreases rapidly with time, for example, $F(t=383$ days $)<0.002$, the dissolved condensate's content would have become very small due to an effective biodegradation and surface evaporation mechanisms. Figure $7 \mathrm{~d}$ indeed shows that the contaminant would 


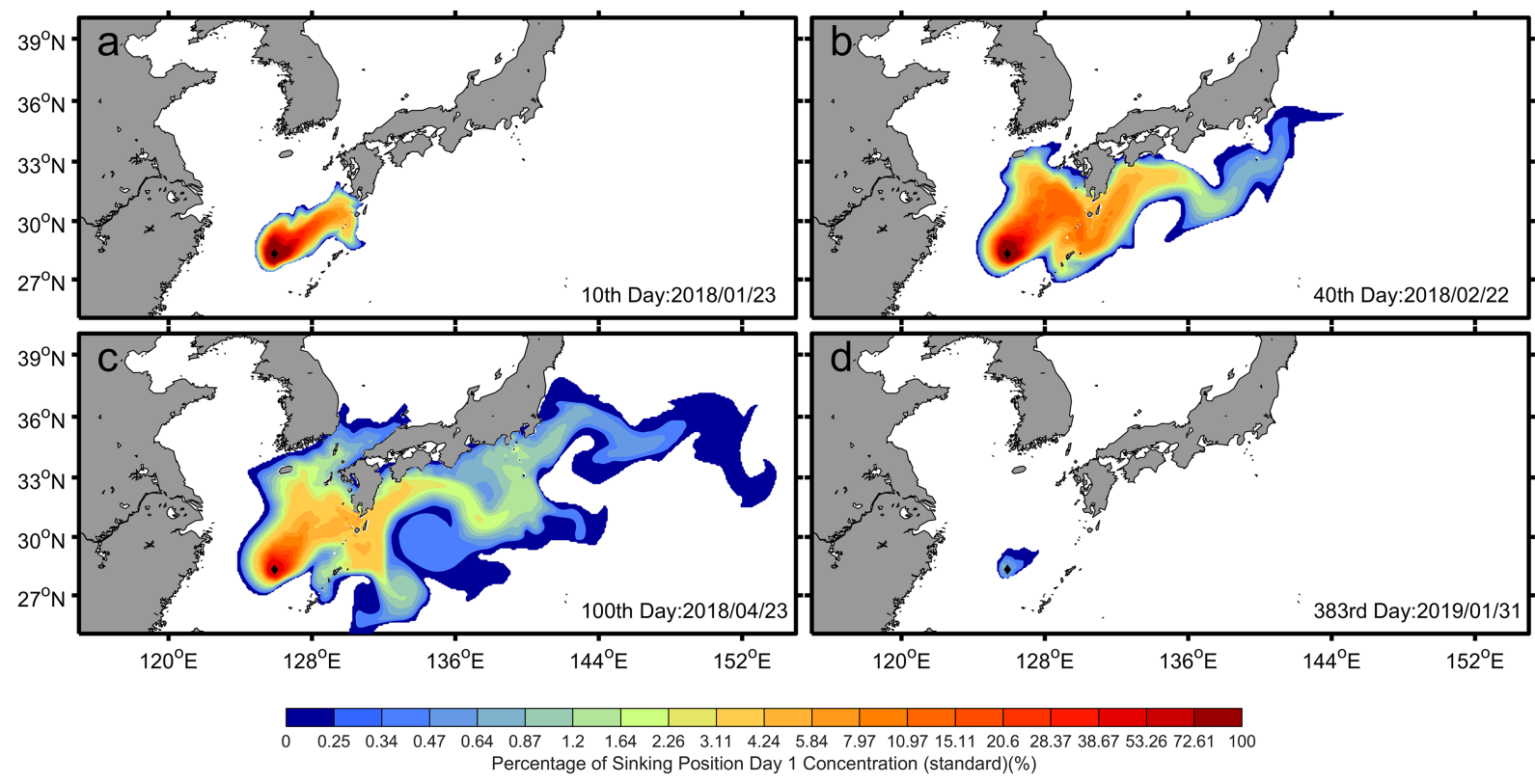

Figure 7. The same as Figure 2 except that the leakage rate decreases exponentially according to equation (6). The concentration in the first 100 days is still significant, but the biodegradation effectively depletes the condensates after the leakage rate becomes negligible. Several other experiments were conducted using longer (and more realistic) biodegradation time scales. For instance, the magnitude of $q$ remains relatively high even on the last simulation day when using 365 days as the $e$-folding biodegradation time scale.

be nearly undetectable except near the wreckage. We would like to point out that the dissolved condensate level could remain in the water much longer if the biodegradation coefficient is smaller (not shown here). For the case of using 365 days for the $e$-folding biodegradation time, the whole model area remains affected on the final day of the simulation ( $383^{\text {rd }}$ day) even though the leakage has become negligible long before that.

\section{Summary and Discussion}

In this study we construct a model to assess the dispersion of dissolved hydrocarbons from the sunken Iranian tanker Sanchi. The premise is that some portions of low molecular weight hydrocarbons in condensates dissolved in seawater as they leaked from the capsized tanker at $110 \mathrm{~m}$ below sea surface. The bottom water at the wreckage site would therefore be enriched by dissolved condensate components. The model is used to examine the lateral and temporal dispersion of contaminant water from the source to the broad area. The contaminant water is treated as a passive tracer in our model, meaning that its variability does affect dynamical processes. It is dispersed by three-dimensional diffusion and advection, depleted by condensate-consuming microbes and evaporated from the sea surface. The latter two processes are treated in the model with some simple parameterizations. The advection is calculated using the output from a high-resolution ocean general circulation model. The objective of this study is not to provide a quantitative assessment of the magnitude and scope of pollution from this incident. This task has become impossible because of no observation in the months following the incident. Instead, the purpose of this study is to illuminate that dissolved hydrocarbons, though invisible to the naked eye, can be spread effectively over a broad area within a relatively short time, for example, days, when the leakage source is near a major WBC.

We have tested the model's sensitivity to each parameter. It is found that the depth-integrated content of the contaminant and its distribution water are rather insensitive to surface evaporation. Evaporation removes condensates from the surface layer but does not significantly affect the content in subsurface layers. The core of the subsurface plume remains little changed in all experiments with different evaporation coefficient $\gamma$. It is found that the model result is most sensitive to the biodegradation parameter $\lambda$ in equation (2). In the control run, we use an $e$-folding time scale of 30 days for biodegradation. This short time scale represents a scenario with a very aggressive and effective degradation process. With more moderate values of $\lambda$, such 
as $1 /(100$ days $)$ or $1 /(365$ days $)$, the polluted area expands to China's coastal water and well into the deep Pacific Ocean through the Kuroshio extension.

In this paper we also test a hypothetical scenario where the tanker capsized at the site of collision instead of drifting more than $200 \mathrm{~km}$ seaward toward the Kuroshio Current. The collision site (marked by the magenta dot in Figure 1) is much closer to China's coast but further away from the Kuroshio Current. Did its 8 day and $200 \mathrm{~km}$ drift actually spare the China's coastal water from pollution at the expense of Japan's east coast? Our simulations show that the contaminant water would stay on the ECS and then flow into the Japan Sea. It would not enter the Kuroshio Current and would have spared Japan's east coast and the open Pacific Ocean from condensate pollution.

In the control run we assume that the leakage is steady in time. In reality one would expect that the leakage will gradually reduce. We conducted an additional experiment by assuming that the leakage decreases exponentially with the $e$-folding time scale of 60 days. Indeed, the magnitude of $q$ is much reduced due to a rapidly decreasing leakage rate. We stress that without observations the specification of how the leakage changes with time is arbitrary in our experiments. The purpose is to demonstrate the sensitivity to various processes and parameters.

\section{Acknowledgments}

Chris Reddy at WHOI provided

invaluable guidance at the beginning of this study. Jian Zhao at UMD

participated in some early discussions and helped the model development. Lei Chen has been financially supported by China Scholarship Council to study at WHOI for 2 years as a WHOI guest student. Jiayan Yang's participation in this study has been supported by the Woods Hole Oceanographic Institution-Ocean University of China (WHOI-OUC) Collaborative Initiative and the W. Van Alan Clark Chair for Excellence in Oceanography from WHOI. This work is supported by National Natural Science Foundation of China major project (41490640, 41490643). The daily oceanic velocity field used in the model is Global Ocean Sea Physical Analysis and Forecasting Products distributed by CMEMS, which can be available online (http://marine. copernicus.eu/services-portfolio/ access-to-products $/$ ?option $=\mathrm{com}_{-}$ csw\&view=details\&product_id= GLOBAL_ANALYSIS_FORECAST_ PHY_001_024). The model output data are available freely from the database of ZENODO (https://zenodo.org/record/ 3405388\#.XXk-5yhKhPY).

\section{References}

API (American Petroleum Institute) (2010). Robust summary of information on Kerosene/Jet fuel. Submitted to the U. S Environmental Protection Agency. Consortium Registration No. 1100997. Washington (DC): American Petroleum Institute, Petroleum HPV Testing Group. Washington (DC). Retrieved from http://www.petroleumhpv.org/petroleum-substances-and-categories/kerosene-jet-fuel

Beardsley, R. C., Limeburner, R., Yu, H., \& Cannon, G. A. (1985). Discharge of the Changjiang (Yangtze River) into the East China Sea. Continental Shelf Research, 4(1-2), 57-76. https://doi.org/10.1016/0278-4343(85)90022-6

Chao, Y., \& Fu, L. (1995). A comparison between the TOPEX/POSEIDON data and a global ocean general circulation model during 1992-1993. Journal of Geophysical Research, 100(C12), 24,965-24,976. https://doi.org/10.1029/95JC02260

Cho, Y. K., \& Kim, K. (2000). Branching mechanism of the Tsushima Current in the Korea Strait. Journal of Physical Oceanography, 30(11), 2788-2797. https://doi.org/10.1175/1520-0485(2000)030<2788:BMOTTC $>2.0 . C O ; 2$

CONCAWE (Conservation of Clean Air and Water in Europe) (1983). Characteristics of petroleum and its behaviour at sea. CONCAWE's Oil Spill Clean-up Technology: Special Task Force No. 8. Den Haag (NL) (36 p.).

ConocoPhillips Barossa Project (2017). Hydrocarbon spill modelling (pp. 174). Retrieved from https://static.conocophillips.com/files/ resources/appendix-ksm.pdf

Environment Canada, Health Canada, 2016: Screening assessment petroleum sector stream approach: Natural gas condensate. Available from: http://www.ec.gc.ca/ese-ees/default.asp?lang=En\&n=7933A3C7-1

Fang, G., Zhao, B., \& Zhu, Y. (1991). Water volume transport through the Taiwan Strait and the continental shelf of the East China Sea measured with current meters. In Elsevier oceanography series (Vol. 54, pp. 345-358). Elsevier.

Galimov, E. M., \& Rabbani, A. R. (2001). Geochemical characteristics and origin of natural gas in Southern Iran. Geochemistry International, 39(8), 780-792.

Harrison, W., Winnik, M. A., Kwong, P. T. Y., \& Mackay, D. (1975). Disappearance of aromatic and aliphatic components from small sea-surface slicks. Environmental Science \& Technology, 9(3), 231-234. https://doi.org/10.1021/es60101a006

Hsueh, Y. (1988). Recent current observations in the eastern Yellow Sea. Journal of Geophysical Research, 93(C6), 6875-6884. https://doi.org/10.1029/JC093iC06p06875

Hsueh, Y., Romea, R. D., \& DeWitt, P. W. (1986). Wintertime winds and coastal sea-level fluctuations in the Northeast China Sea. Part II: Numerical model. Journal of Physical Oceanography, 16(2), 241-261. https://doi.org/10.1175/1520-0485(1986)016<0241:WWACSL>2.0. $\mathrm{CO} ; 2$

Huntley, H. S., Lipphardt, B. L., \& Kirwan, A. D. (2011). Surface drift predictions of the deepwater horizon spill: The Lagrangian perspective. Washington, DC: American Geophysical Union.

Katoh, O. (1994). Structure of the Tsushima Current in the southwestern Japan Sea. Journal of Oceanography, 50(3), 317-338. https://doi. org/10.1007/BF02239520

Kida, S., Qiu, B., Yang, J., \& Lin, X. (2016). The annual cycle of the Japan Sea Throughflow. Journal of Physical Oceanography, 46, 23-39. https://doi.org/10.1175/JPO-D-15-0075.1

Lee S. C., Shiu, W. Y., \& MacKay, D. (1990). The long-term weathering of heavy crude oils: Experimental measurements and development of models. Proceedings of the Thirteenth Arctic and Marine Oil Spill Program Technical Seminar, June 6-8, 1990, Edmonton $(\mathrm{AB})$

Lie, H. J., \& Cho, C. H. (1994). On the origin of the Tsushima Warm Current. Journal of Geophysical Research, 99(C12), 25,081-25,091. https://doi.org/10.1029/94JC02425

Lie, H. J., \& Cho, C. H. (2002). Recent advances in understanding the circulation and hydrography of the East China Sea. Fisheries Oceanography, 11(6), 318-328. https://doi.org/10.1046/j.1365-2419.2002.00215.x

Lie, H. J., \& Cho, C. H. (2016). Seasonal circulation patterns of the Yellow and East China Seas derived from satellite-tracked drifter trajectories and hydrographic observations. Progress in Oceanography, 146, 121-141. https://doi.org/10.1016/j.pocean.2016.06.004

Lie, H. J., Cho, C. H., \& Lee, S. (2009). Tongue-shaped frontal structure and warm water intrusion in the southern Yellow Sea in winter. Journal of Geophysical Research, 114, C01003. https://doi.org/10.1029/2007JC004683

Lin, X., \& Yang, J. (2011). An asymmetric upwind flow, Yellow Sea Warm Current: 2. Arrested topographic waves in response to the northwesterly wind. Journal of Geophysical Research, 116, C04027. https://doi.org/10.1029/2010JC006514

Lin, X., Yang, J., Guo, J., Zhang, Z., Yin, Y., Song, X., \& Zhang, X. (2011). An asymmetric upwind flow, Yellow Sea Warm Current: 1. New observations in the western Yellow Sea. Journal of Geophysical Research, 116, C04026. https://doi.org/10.1029/2010JC006513 
Ling, X.-M. (2013). Analysis on storage volatilization and safety influence of southern Pars condensates (in Chinese with English abstract). Journal of Safety Science and Technology, 9(9), 126-131.

Ma, C., Wu, D., Lin, X., Yang, J., \& Ju, X. (2010). An open-ocean forcing in the East China and Yellow seas. Journal of Geophysical Research, 115, C12056. https://doi.org/10.1029/2010JC006179

Ma, C., Wu, D., Lin, X., Yang, J., \& Ju, X. (2012). On the mechanism of seasonal variation of the Tsushima Warm Current. Continental Shelf Research, 48, 1-7. https://doi.org/10.1016/j.csr.2012.08.013

Ma, X., Chang, P., Saravanan, R., Montuoro, R., Hsieh, J.-S., Wu, D., et al. (2015). Distant influence of Kuroshio eddies on North Pacific weather patterns? Scientific Reports, 5, 17785. https://doi.org/10.1038/srep17785

Madec, G., \& Imbard, M. (1996). A global ocean mesh to overcome the North Pole singularity. Climate Dynamics, 12(6), 381-388 https://doi.org/10.1007/BF00211684

NRC (National Research Council) (2003). Oil in the sea III. Inputs, fates, and effects (p. 265). Washington, DC: The National Academies Press.

Qiu, B., \& Chen, S. (2005). Variability of the Kuroshio Extension jet, recirculation gyre, and mesoscale eddies on decadal time scales. Journal of Physical Oceanography, 35(11), 2090-2103. https://doi.org/10.1175/JPO2807.1

Qiu, B., \& Chen, S. (2010). Eddy-mean flow interaction in the decadally modulating Kuroshio Extension system. Deep Sea Research Part II: Topical Studies in Oceanography, 57(13-14), 1098-1110. https://doi.org/10.1016/j.dsr2.2008.11.036

Qiu, B., Toda, T., \& Imasato, N. (1990). On Kuroshio front fluctuations in the East China Sea using satellite and in situ observational data. Journal of Geophysical Research, 95(C10), 18,191-18,204. https://doi.org/10.1029/JC095iC10p18191

$\mathrm{Qu}, \mathrm{T}$. (2002). Depth distribution of the subtropical gyre in the North Pacific. Journal of Oceanography, 58(3), 525-529. https://doi.org/ 10.1023/A:1021221500837

Rabbani, A. R., \& Kamali, M. R. (2005). Source rock evolution and petroleum geochemistry, offshore SW Iran. Journal of Petroleum Geology, 28(4), 413-428. https://doi.org/10.1111/j.1747-5457.2005.tb00091.x

Reddy, C. M., Arey, J. S., Seewald, J. S., Sylva, S. P., Lemkau, K. L., Nelson, R. K., et al. (2012). Composition and fate of gas and oil released to the water column during the Deepwater Horizon oil spill Proceedings of the National Acaemies of. Science, 109(50), 20,229-20,234. https://doi.org/10.1073/pnas.1101242108

RMRI (Risk Management Research Institute) (2007). Quantitative assessment of oil spill risk for the south coast of Newfoundland and Labrador. St. John's (NL): RMRI. For Transport Canada. Draft Ref CAN/0179/R003. Synopsis report available from: http://www.tc.gc. ca/publications/en/tp14740/pdf/hr/tp14740e.pdf

S. L. Ross Environmental Research Ltd. (1982). The behaviour and fate of gas and condensate spills, for Mobil Oil Canada Ltd.'s Venture gas field development on the Scotian Shelf. $85 \mathrm{pp}$.

Slater, G. F., Nelson, R. K., Kile, B. M., \& Reddy, C. M. (2006). Intrinsic bacterial biodegradation of petroleum contamination demonstrated in situ using natural abundance, molecular-level 14C analysis. Organic Geochemistry, 37(9), 981-989. https://doi.org/10.1016/j. orggeochem.2006.06.014

Tak, Y. J., Cho, Y. K., Seo, G. H., \& Choi, B. J. (2016). Evolution of wind-driven flows in the Yellow Sea during winter. Journal of Geophysical Research: Oceans, 121, 1970-1983. https://doi.org/10.1002/2016JC011622

Takikawa, T., Yoon, J. H., \& Cho, K. D. (2005). The Tsushima warm current through Tsushima Straits estimated from ferryboat ADCP data Journal of Physical Oceanography, 35(6), 1154-1168. https://doi.org/10.1175/JPO2742.1

Tan, Y. (2012). Study on first processing of Iran South Pars condensate oil in Sinopec Guangzhou Company (in Chinese with English abstract). Petroleum Refinery Engineering, 42(2), 26-30.

Teague, W. J., Hwang, P. A., Jacobs, G. A., Book, J. W., \& Perkins, H. T. (2005). Transport variability across the Korea/Tsushima Strait and the Tsushima Island wake. Deep Sea Research Part II: Topical Studies in Oceanography, 52(11-13), 1784-1801. https://doi.org/10.1016/j. dsr2.2003.07.021

Uda, M. (1934). Results of simultaneous oceanographic investigations in the Japan Sea and its adjacent waters during October and November 1933. Journal of Imperial Fishery Experimental Station, 7, 91-151.

Uda, M. (1935). The results of simultaneous oceanographical investigations in the North Pacific Ocean adjacent to Japan made in August, 1933. Journal of Imperial Fisheries Experimental Station, 6, 1-130.

Wang, S., Zhang, Q., Wang, J., \& Tian, S. (2012). Characteristic of sulfur containing compounds in South Pars condensate and its corrosion behavior. Petroleum Processing and Petrochemicals, 43(3), 88-91. (In Chinese with English abstract)

Wang, S. D., Shen, Y. M., \& Zheng, Y. H. (2005). Two-dimensional numerical simulation for transport and fate of oil spills in seas. Ocean Engineering, 32(13), 1556-1571. https://doi.org/10.1016/j.oceaneng.2004.12.010

Yang, D., Yin, B., Liu, Z., Bai, T., Qi, J., \& Chen, H. (2012). Numerical study on the pattern and origins of Kuroshio branches in the bottom water of southern East China Sea in summer. Journal of Geophysical Research, 117, C02014. https://doi.org/10.1029/2011JC007528

Yin, L., Zhang, M., Zhang, Y., \& Qiao, F. (2018). The long-term prediction of the oil-contaminated water from the Sanchi collision in the East China Sea. Acta Oceanologica Sinica, 37(3), 69-72. https://doi.org/10.1007/s13131-018-1193-5

Zhou, Y.-Q. (2012). Measures to reduce volatility of oil condensate (in Chinese with English abstract). Value Engineer, 48-49. 